\title{
A cultura do Arachis hypogaea L.: Uma revisão
}

\author{
The culture of Arachis hypogaea L.: A review \\ El cultivo de Arachis hypogaea L.: Una revisión
}

Recebido: 05/02/2021 | Revisado: 06/02/2021 | Aceito: 06/02/2021 | Publicado: 09/02/2021

\author{
Andressa Alves Cabreira dos Santos \\ ORCID: https://orcid.org/0000-0001-6731-9575 \\ Universidade do Estado de Mato Grosso, Brasil \\ E-mail: acabreyra@gmail.com \\ Altacis Junior de Oliveira \\ ORCID: https://orcid.org/0000-0002-6787-7160 \\ Universidade do Estado de Mato Grosso, Brasil \\ E-mail: altacismarquesfig@hotmail.com \\ Taniele Carvalho de Oliveira \\ ORCID: https://orcid.org/0000-0002-6900-6449 \\ Universidade do Estado de Mato Grosso, Brasil \\ E-mail: tani.ele@hotmail.com \\ Anny Karoline Neves da Cruz \\ ORCID: https://orcid.org/0000-0002-3506-4130 \\ Universidade do Estado de Mato Grosso, Brasil \\ E-mail: anny.karolyne026@gmail.com \\ Mirian da Silva Almici \\ ORCID: https://orcid.org/0000-0001-9467-7060 \\ Universidade do Estado de Mato Grosso, Brasil \\ E-mail: mirianalmici@hotmail.com
}

\begin{abstract}
Resumo
O amendoim (Arachis hypogaea L.) é uma das oleaginosas mais cultivadas no mundo, originária da América do Sul e pertencente à família Fabaceae. É uma cultura que se desenvolve bem em diferentes condições de temperaturas, clima e solo, de maneira que, é considerada uma planta rústica, porém, requer cuidados específicos para se obter uma boa produtividade. A cultura tem grande importância econômica por estar ligada diretamente com a indústria, por possuir alto valor nutricional, com uma composição rica em óleo e proteínas. Logo é utilizada com diversas finalidades, desde consumo in natura, torrado, confeitaria, como na indústria alimentícia onde se faz pastas, extração de óleo ou ainda para produção de farelo, destinada a alimentação animal. O cultivo do amendoim é feito em todo o Brasil. A região sudeste se destaca por ser a maior produtora, tendo São Paulo como o maior estado produtor. Desta forma, a concentração de estudos é voltada para estas áreas, bem como na região Nordeste, em que o cultivo é feito em condições de sequeiro. Tendo em vista os aspectos observados o presente trabalho foi desenvolvido com o objetivo de apresentar uma revisão de literatura, pois, é fundamental para auxiliar leitores com informações apropriadas, para consequente melhoria na produção desta cultura.
\end{abstract}

Palavras-chave: Amendoim; Cultivo; Produção.

\begin{abstract}
The peanuts (Arachis hypogaea L.) are one of the most cultivated oilseeds in the world, native to South America and belonging to the Fabaceae family. It is a crop that develops well in different conditions of temperature, climate and soil, so it is considered a rustic plant, but requires specific care to obtain good productivity. The crop is of great economic importance because it is directly linked to the industry, has high nutritional value, with a composition rich in oil and proteins. Soon it is used for several purposes, from natural consumption, toast, confectionery, as in the food industry where pasta is made, oil extraction or even for the production of bran, destined for animal feed. Peanut cultivation is done all over Brazil. The Southeast region stands out for being the largest producer, with São Paulo as the largest producing state. This way, the concentration of studies is directed to these areas, as well as in the Northeast region, where the cultivation is done in dry conditions. Considering the observed aspects, this work was developed with the objective of presenting a literature review, because it is fundamental to help readers with appropriate information, for consequent improvement in the production of this culture.
\end{abstract}

Keywords: Peanut; Cultivation; Production.

\section{Resumen}

El cacahuete (Arachis hypogaea L.) es una de las semillas oleaginosas más cultivadas del mundo, originaria de Sudamérica y perteneciente a la familia de las fabáceas. Es un cultivo que se desarrolla bien en diferentes condiciones de temperatura, clima y suelo, por lo que se considera una planta rústica, pero que requiere cuidados específicos para 
obtener una buena productividad. El cultivo tiene una gran importancia económica porque está directamente vinculado a la industria, tiene un alto valor nutricional, con una composición rica en aceite y proteínas. Pronto se utiliza para varios fines, desde el consumo natural, el tostado, la confitería, como en la industria alimentaria donde se elabora la pasta, la extracción de aceite o incluso para la producción de salvado, destinado a la alimentación animal. El cultivo del cacahuete se realiza en todo Brasil. La región sureste destaca por ser la mayor productora, con São Paulo como mayor estado productor. Por ello, la concentración de estudios se centra en estas zonas, así como en la región del noreste, donde el cultivo se realiza en condiciones de sequedad. Teniendo en cuenta los aspectos observados, el presente trabajo se desarrolló con el objetivo de presentar una revisión bibliográfica, ya que es fundamental para ayudar a los lectores con información adecuada, para la consecuente mejora en la producción de este cultivo.

Palabras clave: Cacahuete; Cultivo; Producción.

\section{Introduçãa}

O amendoinzeiro é uma planta pertencente ao grupo das oleaginosas originária da América do Sul. Foi distribuído em várias partes do mundo através dos portugueses (Lima, 2011). Compartilhando desta mesma ideia, Macêdo (2007) diz que, essa leguminosa cientificamente classificada como Arachis hypogaea, tenha se originado entre o sul da Bolívia e o norte da Argentina. E posteriormente, foi disseminada em outras regiões asiáticas de forma irreversível pelos espanhóis e portugueses.

Até o início dos anos 1970, o Brasil foi um importante produtor de amendoim. São Paulo e Paraná são os principais países produtores, respondendo por $90 \%$ da produção nacional. Este produto é projetado para fornecer farelo para ração animal e óleo vegetal para consumo direto, mas também para fabricação de produtos industriais Como margarina. Na mesma década, diversos fatores políticos e econômicos contribuíram para A expansão da soja mudou a imagem da produção e do consumo de amendoim no Brasil (De Freitas et al., 2005).

Devido ao sistema de produção rotativo, ou seja, nas áreas de renovação dos canaviais e das pastagens, a maioria dos produtores (pequenos e médios produtores) é arrendatária. Nas fazendas de cana-de-açúcar, 15\% a 20\% da área plantada é com amendoim a cada ano (Dalva, 2016).

Do ponto de vista botânico, os amendoins são divididos em três tipos: o tipo Virgínia representa as plantas com hábito de crescimento baixo, semi-baixo e anão, e sua colheita tardia, ou seja, ciclo longo (120 a 140 dias) e duas sementes; os tipos de Valência e Espanhóis são representados por variedades que têm o hábito de crescer em pé ou semi-vertical e têm um período curto (90 a 100 dias). A equipe espanhola forneceu duas sementes de pequeno e médio porte aos frutos. As vagens do grupo Valencia contêm 2 a 4 sementes em cada vagem (Godoy et al., 2005).

De acordo com Vieira et al. (2001), a planta é herbácea, ereta ou prostrada, anual, com ciclo que varia entre 90 e 160 dias, podendo assim, atingir uma altura entre 15 e $50 \mathrm{~cm}$, dependendo do hábito de crescimento. É uma planta alotetraplóide, que se reproduz quase exclusivamente por autogamia (Santos et al., 2000).

Apresenta folhas compostas, pinada, com dois pares de folíolos inseridos num pecíolo de 4 a $9 \mathrm{~cm}$. A inserção dos folíolos é oposta, apresentando a forma elíptica e lanceolada, dependendo da cultivar. Os estômatos estão presentes nas duas superfícies foliares, adaxial e abaxial (Nogueira e Távora, 2005).

Diante da importância de se conhecer as principais características sobre esta cultura, o presente trabalho teve por objetivo apresentar uma revisão de literatura para auxiliar leitores com informações apropriadas, para consequente melhoria na produção desta cultura.

\section{Metodologia}

A proposta desse artigo foi apresentar uma revisão com alguns pontos conceituais e considerações que de certa forma reforçam entre si nos apoios de contextualização teórica sobre o cultivo de Arachis hypogaea L. A pesquisa apresentada neste artigo foi realizada com base em estudos bibliográficos, realizada em artigos científicos, boletins técnicos, livros e revistas. 


\section{Amendoim (Arachis hypogaea L.)}

A cultura do amendoim possui algumas particularidades que nos permitem observar suas características morfológicas, como podemos ver nos apontamentos de Nogueira e Távora (2005), onde dizem que: a flor é completa, perfeita, hermafrodita, com coroa de borboleta, de cor amarela, é agrupada em números variáveis ao longo do ramo principal ou secundário, dependendo da variedade. O período de floração é intenso, com períodos de maior emergência de flores, e o processo de frutificação ocorre por meio da geocarpia, na qual a flor aérea, quando fertilizada, produz um fruto subterrâneo por meio de um ginóforo.

As sementes, proveniente dos óvulos, constituem a parte de maior interesse econômico, por ser um alimento nutritivo e com alto teor de óleo comestível, seu número pode variar entre 1 a 6 , sua proporção varia de acordo com a cultivar e as condições do plantio (Nogueira e Távora, 2005).

O sistema radicular do amendoim é extenso e ramificado, apresentando raiz pivotante com ramificações laterais, o que propicia rápido crescimento inicial (Peixoto et al., 2008).

\section{Ecofisiologia}

Para a cultura do amendoim, é importante que ocorra temperaturas elevadas, pois de acordo com Nogueira e Távora (2005), as temperaturas consideradas ideais para o desenvolvimento dessa cultura se encontram entre 25 e $35^{\circ} \mathrm{C}$.

De acordo com Cato et al. (2008), a disponibilidade hídrica para o amendoinzeiro varia de 450 a $700 \mathrm{~mm}$, pois o mesmo é considerado relativamente tolerante à seca, devido ao seu sistema radicular profundo, permitindo assim explorar as camadas mais profundas de volume de solo, sendo elas as que possuem água disponível em maior quantidade.

$\mathrm{O}$ amendoinzeiro tem metabolismo fotossintético do tipo $\mathrm{C} 3$ e apresenta taxa fotossintética líquida máxima a $30{ }^{\circ} \mathrm{C}$ e a máxima taxa de produção de matéria seca, ou produtividade da cultura, é de 19,6 g m- 2 dia-1 (Embrapa, 2009). Nogueira e Távora (2005) relatam que não há efeito do fotoperíodo nas plantas do amendoim, ou seja, é considerada uma planta neutra. A luz não é considerada um fator limitante para a fotossíntese em condições de campo, porém se ocorre exposição da extremidade dos ginóforos a luz, isso pode provocar um desenvolvimento anormal dos frutos.

Nos dias atuais o amendoim é uma das culturas agrícolas que pode produzir mais alimentos no mesmo espaço agrícola, isso a partir de variedades mais produtivas, nutritivas e resistentes, a serem obtidas com as ferramentas da biotecnologia e da genômica (Ramos e Barros, 2014).

Em nível de Brasil a área plantada em hectare com amendoim era em 2004 de 105.434 e esse número subiu para 154.912 em 2016. E nesse mesmo ano, conforme o último censo o rendimento no Brasil, foi de 3.654 kg há (IBGE, 2016).

$\mathrm{O}$ amendoim possui diversas formas de uso destacando-se in natura, ou seja, na forma de grãos, cozidos ou também torrados, farinha, óleo, farelo e na indústria farmacêutica. É muito rico em vitamina E, e em proteína, sendo uma importante fonte de energia e aminoácidos para alimentação humana (Ramos e Barros, 2014).

Apesar de ser considerado rústico, a cultura do amendoim exige um manejo específico para se alcançar uma boa produção (Suassuna, 2014). O pH considerado ótimo para a cultura situa-se entre 6 e 6,5 (Santos et al., 1996), sendo importante a manutenção do $\mathrm{pH}$ do solo dentro da faixa ótima de cultivo para que não ocorram deficiências nutricionais, tais como: cálcio, molibdênio e fósforo.

O cultivo do amendoim é geralmente provindo de pequenos produtores, utilizando-se assim para realizar todas as atividades de manejo, desde o plantio até a colheita a mão-de-obra familiar (Suassuna et al., 2006). De acordo com Beltrão et al. (2011) esta cultura apresenta um melhor desenvolvimento em solos bem drenados, que possuem uma textura arenosa, porém, também crescem com facilidade em uma maior diversidade de solos. Em pesquisas realizadas pela Embrapa (2009), o 
solo deve apresentar além de uma boa drenagem, uma boa aeração, beneficiando no desenvolvimento de raízes e também de frutos. A planta tem natureza hipógea, ou seja, os frutos desenvolvem- se debaixo do solo (Aquino et al., 2013).

As recomendações de espaçamento para cultivares com hábito de crescimento rasteiro varia de 0,8 a $0,9 \mathrm{~m}$ entre linhas, com densidade de semeadura de 12 a 15 sementes por metro, enquanto que para as cultivares eretas, o espaçamento mais recomendado é 0,5 x 0,2 m, com duas sementes por cova (Embrapa, 2009).

A semeadura deve ser feita em profundidade de $5 \mathrm{~cm}$, tanto para o plantio manual ou em sistema mecanizado, pois em semeadura rasa, a germinação pode ser comprometida, devido à rápida secagem da camada superficial do solo (Embrapa, 2009).

É importante que o solo disponibilize nutrientes para a planta em quantidades suficientes para o seu pleno desenvolvimento e produção. O nitrogênio é indispensável para o desenvolvimento vegetativo das plantas, devido seu papel na composição de vários compostos orgânicos, incluindo aminoácidos e ácidos nucleicos (Melo, 2013). O fósforo, embora seja requerido em menores quantidades, atua na produtividade da cultura, aumentando a eficiência reprodutiva e também no enchimento dos frutos. Por sua vez, o cálcio tem influência tanto na fisiologia da planta quanto na reação do solo. Pois, quando incorporado ao solo, controla o pH, além disso, aumenta a disponibilidade de elementos essenciais para as plantas (Embrapa, 2009).

Conforme Moraes (2006) a cultura do amendoim é afetada por doenças que podem causar redução de até mais de 50\% na produção de vagens, quando medidas de controle não são empregadas. Podendo ocorrer tanto durante todo período de desenvolvimento das plantas, como até mesmo depois da colheita. Logo, as principais doenças que comprometem este cultivo são: a mancha-castanha, pinta-preta, ferrugem, verrugose, mofo-branco e murcha do sclerotium (Coutinho e Suassuna, 2014).

Outro fator existente que pode prejudicar a cultura são as pragas. Algumas possuem hábito subterrâneo, destacando-se a lagarta-elasmo, lagarta-rosca, o percevejopreto e o percevejo-castanho. Porém, há ainda as pragas que atacam a parte aérea da planta sendo as principais: tripes, cigarrinha-verde, os ácaros rajados e vermelho, lagartado-pescoço vermelho e também a lagarta-militar (Embrapa, 2009).

A colheita do amendoim pode ser feito de três modos, sendo elas: manualmente, geralmente feita por pequenos produtores, onde as plantas são retiradas em arranquío manual; sistema semi-mecanizado onde primeiramente é realizado o corte das raízes e depois é feito enleiramento manual, utilizando-se implemento tracionado por trator; e pode ser feita de maneira mecanizada, sendo está dividida em duas etapas, onde a primeira é feito o arranquio e o enleiramento das plantas com um equipamento denominado arrancador-enleirador e a segunda após a secagem das vagens ao sol, é feito recolhimento e batedura das plantas, separando as vagens da planta (Embrapa, 2009).

\section{Conclusão}

Com base nas informações apresentadas neste estudo derivado de uma revisão bibliográfica, pode- se fornecer para a comunidade acadêmica, pequenos produtores e leitores afins elementos e informações adequadas sobre os principais requisitos no cultivo de amendoim a fim de contribuir para melhoria nos métodos de produção.

Embora a soja seja a principal cultura produzida em nosso país, a produção de amendoim está aumentando no Brasil, crescendo a uma taxa média anual de $12 \%$. O cultivo dessa oleaginosa está promovendo a renovação dos canaviais ou das pastagens, em Minas Gerais e novas regiões, como os estados do centro e oeste, têm potencial de desenvolvimento.

A partir desses dados, entende-se que novas pesquisas podem ser realizadas buscando definições específicas de cultivo para cada nova região produtora, visto que condições edafoclimáticas são excepcionais para um bom desenvolvimento da cultura. Sendo assim, são importantes para a linha desenvolvida neste trabalho e relevantes para literatura de forma geral. 


\section{Referências}

Aquino, E. L., Santos, A., Souza, G., \& Silva, P. C. C. (2017). Plantas de amendoim (Arachis hypogeae 1.) submetidas à diferentes doses de alumínio em solução nutritiva. Enciclopédia biosfera, Centro Científico Conhecer-Goiânia, 9(16), 1698.

Beltrão, N. E. M., Sousa Junior, S. P., Oliveira, M., Fideles Filho, J., \& Silva, M. (2011). Ecofisiologia do amendoim. Ecofisiologia das culturas de algodão, amendoim, gergelim, mamona, pinhão-manso e sisal. Embrapa Informação Tecnológica, Brasília, 125-162.

Cato, S. C, Albert, L. H. B., Monteiro, A. C. B. A. Amendoinzeiro. Castro, P. R., Castro, P. R., Kluge, R. A., \& Sestari, I. (2008). Manual de fisiologia vegetal: fisiologia de cultivos. Agronômica Ceres.

Coutinho, W, M., \& Suassuna, N, D. (2014, janeiro de 2021) Sistema de Produção de Amendoim: Manejo integrado de doenças. Recuperado de: https://www. spo.cnptia.embrapa.br/conteudo?p_p_id=conteudoportlet_WAR_sistemasdeproducaolf6_1ga1ceportlet\&p_p_lifecycle=0 $\& p \_p \_s t a t e=n o r m a l \& p \_p \_m o d e=v i e$ w\&p_p_col_id=column1\&p_p_col_count=1\&p_r_p_76293187_sistemaProducaoId=3803\&p_r_p_996514994_topicoId=3452>.

De Freitas, S.M; Martins, S.S; Nomi, A.K; \& Campos, A.F. (2005). Evolução do mercado brasileiro de amendoim. In: dos Santos, R. C. (Ed.). O agronegócio do amendoim no Brasil. Empresa Brasileira de Pesquisa Agropecuária, Embrapa Algodão, Ministério da Agricultura e do Abastecimento.

EMBRAPA - Empresa Brasileira de Pesquisa Agropecuária. (2009) Amendoim: o produtor pergunta, a Embrapa responde. Brasília.

Gabriel, D. (2016). Pragas do Amendoim. Instituto Biológico, 2016. (Documento técnico, 26).

Godoy, I. J., Moraes, S. A., Zanotto, M. D., \& Santos, R. C. (2005). Melhoramento em Amendoim. In: BORÉM, A. Melhoramento de Espécies Cultivadas Ed. Viçosa: UFV.

IBGE: Instituto Brasileiro de Geografia e Estatística. (2016, janeiro de 2021) Censo de Produção Agrícola. 2016. Recuperado de:http://www2.sidra.ibge. gov.br/bda /tabela /listabl.asp?z=t\&c=1000\#nota.

Lima, T. M. D. (2011). Cultivo do amendoim submetido a diferentes níveis de adubação e condições edafoclimáticas no sudoeste de Goiás.

Macêdo, M, H, G. (2007, janeiro de 2021) Amendoim: proposta de preço Mínimo - safra 2006/2007. Recuperado de: <http://www.conab.gov.br/Olala CMS/uploads /arquivos /83e31b69fc4c1f45a1cee5eb53797f41.pdf>.

Melo, E. B. S. (2013). Parâmetros fisiológicos em genótipos de amendoim inoculados com Bradyrhizobium.

Moraes, S. A. (2006, janeiro de 2021) Amendoim: Principais doenças, manejo integrado e recomendações de controle. 2006. Recuperado de: http://www.infobibos.com/Artigos/2006_2/amendoim/Index.htm

Nogueira, R., \& Távora, F. (2005). Ecofisiologia do amendoim (Arachishipogaea L.).

Peixoto, C. P., Gonçalves, J. A., Peixoto, M. D. F. D. S. P., \& Carmo, D. O. D. (2008). Características agronômicas e produtividade de amendoim em diferentes espaçamentos e épocas de semeadura no recôncavo baiano. Bragantia, 67(3), 673-684.

Ramos, G. A.; \& Barros, M. A. L. (2014, janeiro de 2021) Sistema de Produção de Amendoim. Recuperado de: https://www.spo.cnptia.embrapa.br/ conteudo?p_p_id=conteudoportlet_WAR_sistemasdeproducaolf6_1ga1 ceportlet\&pp_lifecycle=0\&\&p_p_state=normal\&p_p_mode=view\&p_p_col_id=column 1\&p_p_col_count=1\&p_r_p_76293187_sistemaProducaoId=3803\&p_r_p_-996514994_topicoId=3445.

Santos, R. C. D., Moreira, J. D. A. N., Farias, R. H. D., \& Duarte, J. M. (2000). Classificação de genótipos de amendoim baseada nos descritores agromorfológicos e isoenzimáticos. Ciência Rural, 30(1), 55-59.

Santos, R. D., Vale, L. V., Silva, R., Almeida, R. D., \& Almeida, V. M. R. A. (1996). Recomendações técnicas para o cultivo de amendoim precoce no período das águas. Campina Grande: Embrapa-CNPA, 1996b. 21p. (Circular técnica, 20).

Suassuna, T, M, F. (2014, janeiro de 2021) Sistema de Produção de Amendoim: Produção e mercado. Recuperado de: https://www.spo.cnptia.embrapa.br/conteudo?p_p_id=conteudoportlet_WAR_sistemasdeproducaolf6_1ga1ceportlet\&p_p_lifecycle=0\&p_p_state=normal\&p_ p_mode=view\&p_p_col_id=column1\&p_p_col_count=1\&p_r_p_76293187_sistemaProducaoId=3803\&p_r_p_-996514994_topicoId=3445.

Suassuna, T., Santos, R., \& Gondim, T. (2006). Cultivo do amendoim: importância econômica. Campina Grande: Embrapa Algodão.

Vieira, R. F., Vieira, R. F., Vieira, C., \& Vieira, R. F. (2001). Leguminosas graníferas. Viçosa: UFV. 